\title{
BMJ Open The impact of funding deadlines on personal workloads, stress and family relationships: a qualitative study of Australian researchers
}

\author{
Danielle L Herbert, ${ }^{1}$ John Coveney, ${ }^{2}$ Philip Clarke, ${ }^{3}$ Nicholas Graves, ${ }^{1}$ \\ Adrian G Barnett ${ }^{1}$
}

To cite: Herbert DL, Coveney J, Clarke P, et al. The impact of funding deadlines on personal workloads, stress and family relationships: a qualitative study of Australian researchers. BMJ Open 2014;4:e004462. doi:10.1136/bmjopen-2013004462

- Prepublication history for this paper is available online. To view these files please visit the journal online (http://dx.doi.org/10.1136/ bmjopen-2013-004462).

Received 12 November 2013 Revised 18 February 2014 Accepted 27 February 2014

CrossMark

For numbered affiliations see end of article.

Correspondence to Assoc/Prof Adrian G Barnett; a.barnett@qut.edu.au
ABSTRACT

Objective: To examine the impact of applying for funding on personal workloads, stress and family relationships.

Design: Qualitative study of researchers preparing grant proposals.

Setting: Web-based survey on applying for the annual National Health and Medical Research Council (NHMRC) Project Grant scheme.

Participants: Australian researchers ( $n=215)$.

Results: Almost all agreed that preparing their proposals always took top priority over other work (97\%) and personal $(87 \%)$ commitments. Almost all researchers agreed that they became stressed by the workload (93\%) and restricted their holidays during the grant writing season (88\%). Most researchers agreed that they submitted proposals because chance is involved in being successful (75\%), due to performance requirements at their institution $(60 \%)$ and pressure from their colleagues to submit proposals (53\%). Almost all researchers supported changes to the current processes to submit proposals (95\%) and peer review $(90 \%)$. Most researchers $(59 \%)$ provided extensive comments on the impact of writing proposals on their work life and home life. Six major work life themes were: (1) top priority; (2) career development; (3) stress at work; (4) benefits at work; (5) time spent at work and (6) pressure from colleagues. Six major home life themes were: (1) restricting family holidays; (2) time spent on work at home; (3) impact on children; (4) stress at home; (5) impact on family and friends and (6) impact on partner. Additional impacts on the mental health and well-being of researchers were identified.

Conclusions: The process of preparing grant proposals for a single annual deadline is stressful, time consuming and conflicts with family responsibilities. The timing of the funding cycle could be shifted to minimise applicant burden, give Australian researchers more time to work on actual research and to be with their families.

\section{INTRODUCTION}

A large amount of time is invested by academics in preparing funding proposals to support their research. A successful proposal

\section{Strengths and limitations of this study}

- This is the first Australian study providing empirical evidence of the significant negative impact of applying for a single annual funding deadline on researchers' productivity, health and well-being.

- This study found that the process of preparing grant proposals is stressful, time consuming and conflicts with responsibilities for children and family.

- Researchers responding to the survey may not be representative of the complete population of researchers; however, they did report a history of successfully gaining funding.

- The costs to the mental health and well-being of the researcher or their family members could not be quantified in this study and requires further examination.

provides an obvious pay-off, but the costs could be felt personally with stress placed on private lives during grant writing seasons and subsequent rebuttal periods. Despite the worldwide importance of research funding and peer review processes, there is little evidence on the personal costs on researchers to prepare funding proposals.

Personal costs could possibly be reduced by streamlining application processes. Some funding agencies have made changes to reduce the burden on applicants and their peer review systems. The US National Institute of Health (NIH) shortened their applications with the intention to reduce the burden on the administration, peer reviewers and applicants. ${ }^{1}$ The UK Engineering and Physical Sciences Research Council trialled strict submission rules for previously unsuccessful applicants to reduce the peer review workload, but this change was met by strong protests from researchers. ${ }^{2}$ The Canadian Institutes of Health Research reviewed their 
funding schemes specifically to reduce applicant workload, ${ }^{3}$ but they did not investigate other areas of personal burden. The RAND Corporation (Europe) has recognised the burden on applicants during the development and refinement of a proposal. ${ }^{4}$ The 2012 McKeon review into Australian research funding recommended the streamlining of grant proposals to minimise the burden on applicants. ${ }^{5}$ These changes are a clear acknowledgement of the workload and other impacts of applying for research funding. However, as yet, these impacts on applicants have not been examined.

In 2012, Australian researchers spent an estimated 550 years preparing 3727 proposals (21\% were funded) for the major National Health and Medical Research Council (NHMRC) funding scheme, at an estimated annual salary cost of $\$$ A66 million. ${ }^{6} 7$ These figures underestimate the total cost because they do not include administrative or technical support, peer review and the personal costs and impacts on family and relationships.

Alberts ${ }^{8}$ stated that the reliance in the USA on NIH funding to expand research capacity is unsustainable when the success rates can be below $10 \%$. The pattern is similar in Australia as the number of proposals submitted to the NHMRC is rising steadily and the success rate declined to $17 \%$ in $2013 .{ }^{9}{ }^{10}$ If this pattern continues, the prediction is that more than 5000 proposals may be submitted to the major NHMRC funding scheme in 2017. ${ }^{11}$ International agencies have implemented initiatives to reduce the total number of proposals being submitted by barring unsuccessful proposals from previous years. $^{2}{ }^{11}$

The European Science Foundation makes the distinction between funding schemes that are either 'managed' by setting timelines and deadlines for each funding cycle, or are 'responsive' to the receipt of proposals for funding cycles that are continuously open. ${ }^{12}$

The NHMRC major funding scheme is 'managed' for a single deadline $e^{9}$ and differs from comparable international funding schemes where multiple deadlines are available or schemes are continuously open, for example, in Canada, ${ }^{3}$ the $\mathrm{UK}^{13}{ }^{14}$ and the $\mathrm{USA}^{15} 16$ (table 1). Funding schemes are expected to be efficient, fair and rational ${ }^{17}$; however, the impact of a single submission deadline has not previously been examined.
This study sets out to ask the researcher about their experience as applicants when preparing funding proposals for a single annual funding deadline and the consequences for their work and home lives.

\section{METHODS}

\section{Study design}

The NHMRC Project Grant is the main scheme for funding health and medical research in Australia and has a single annual deadline for submission. In March 2013, Australian researchers submitted 3916 proposals to the NHMRC Project Grant funding scheme, and 17\% were funded. In May 2013, email invitations to participate in a web-based survey were distributed to the research community through existing networks from previous studies. ${ }^{6}$ The target group was researchers with the experience of applying for a NHMRC Project Grant either in 2013 or previous funding rounds. Researchers responded from May to July 2013 and took 10-20 min to complete the survey depending on how many additional comments they provided.

\section{Survey questions}

The survey questions were developed to ask the researcher about their experience of applying for NHMRC Project Grants. To gauge the representativeness of our sample, we asked for geographical locations (major city, inner regional, outer regional or remote),$^{18}$ academic level (early career (level A) to professor (level E)) and whether the researcher's university belonged to one of eight research-intensive universities known as the Group of Eight (Go8, http://www.go8.edu.au). All Go8 universities are located in major cities, and, in 2012, they received $63 \%$ of all NHMRC funding (\$A408 million). ${ }^{9}$

As indicators of experience with writing proposals and prior success, researchers were asked for the number of NHMRC Project Grants they currently held as a chief investigator (CI) and the number of proposals submitted in March 2013. CIs can hold a maximum of six project grants at one time. The characteristics of the researchers and those providing comments are compared in table 2. The survey included separate sections on personal workloads and motivations to submit proposals. Researchers were asked to rate their agreement (strongly agree to

Table 1 International comparison of submission deadlines

\begin{tabular}{|c|c|c|c|}
\hline Country & Funding agency & Funding scheme & Annual submissions (month) \\
\hline Australia & $\begin{array}{l}\text { National Health and Medical Research Council, } \\
\text { NHMRC }\end{array}$ & Project grant & One (March) \\
\hline Canada & Canadian Institute of Health Research, ClHR & $\begin{array}{l}\text { Open suite of } \\
\text { programmes }\end{array}$ & Two (March, September) \\
\hline UK & $\begin{array}{l}\text { Engineering and Physical Science Research } \\
\text { Council, EPSRC }\end{array}$ & Standard grant & Continuously open \\
\hline UK & Medical Research Council, MRC & Research grant & Three (January, May, September) \\
\hline USA & National Institutes of Health, NIH & $\mathrm{RO1}$ research grant & Three (February, June, October) \\
\hline USA & National Science Foundation, NSF & Programme grant & Continuously open \\
\hline
\end{tabular}


Table 2 Characteristics of the researchers

\begin{tabular}{|c|c|}
\hline Characteristics & $\begin{array}{l}\text { Researchers } \\
(n=215)\end{array}$ \\
\hline Current academic level (example role) & Per cent \\
\hline Level A (assistant lecturer) & 7 \\
\hline Level B (lecturer) & 19 \\
\hline Level C (senior lecturer) & 27 \\
\hline Level D (associate professor) & 15 \\
\hline Level E (professor) & 24 \\
\hline Prefer not to answer & 1 \\
\hline Missing & 7 \\
\hline \multicolumn{2}{|l|}{ Location of primary institution } \\
\hline Major city, Group of Eight (Go8)* & 51 \\
\hline Major city, not Go8 & 37 \\
\hline Regional & 4 \\
\hline Prefer not to answer & 1 \\
\hline Missing & 7 \\
\hline \multicolumn{2}{|l|}{ Chief investigator (Cl) role† } \\
\hline \multicolumn{2}{|l|}{ Grants currently held } \\
\hline None & 32 \\
\hline $1-2$ & 43 \\
\hline $3-4$ & 9 \\
\hline $5-6$ & 4 \\
\hline Missing & 13 \\
\hline \multicolumn{2}{|l|}{ Proposals submitted in the latest round } \\
\hline None & 15 \\
\hline $1-2$ & 49 \\
\hline $3-4$ & 22 \\
\hline $5-6$ & 2 \\
\hline Missing & 12 \\
\hline
\end{tabular}

Percentages may not add to $100 \%$ due to rounding.

${ }^{*}$ Research-intensive university as part of the Go8.

†Funding rules stipulate a maximum of six grants per $\mathrm{Cl}$.

strongly disagree) with the statements in table 3. For presentation purposes, we summarised the responses into agree or disagree. A free-text option was provided for personal workloads after the open-ended prompt: "Please tell us more about the impact of grant writing season on your work and personal life."

\section{Qualitative analysis}

From 239 survey respondents, 24 were excluded from the analysis due to only answering the initial one or two survey questions and having missing data for the majority $(n=10)$; not holding an academic position $(n=12)$ or being a PhD student $(n=2)$. The analysis focused on the 215 researchers who currently held academic positions ( $n=200$, providing 122 comments) or maintained anonymity by not providing their academic level $(n=15$, 5 comments). From the free-text comments for personal workloads, factors relating to researchers' experience of preparing their proposals were identified and explored using thematic analysis. All comments were categorised by academic level and location of primary institution.

The broad themes within each category were examined by DLH and AGB prior to a secondary thematic analysis by JC (an experienced qualitative researcher).
Table 3 Impact of grant writing on the researchers, by location of primary institution

\begin{tabular}{|c|c|c|}
\hline & & $\begin{array}{l}\text { Researchers, } \\
n=215\end{array}$ \\
\hline Personal workloads & Row (\%) & $\begin{array}{ll}\text { Agree } & \text { Disagree }\end{array}$ \\
\hline
\end{tabular}

I give top priority to writing my proposals over my other work commitments

Major city, Group of Eight (Go8)* $\quad 98 \quad 2$

Major city, not Go8 $\quad 95 \quad 5$

Regional $\quad 100 \quad 0$

I give top priority to writing my proposals over my personal commitments

$\begin{array}{lll}\text { Major city, Go8 } & 90 & 10 \\ \text { Major city, not Go8 } & 83 & 17 \\ \text { Regional } & 89 & 11\end{array}$

I get stressed by the workload required to write my proposals

$\begin{array}{lrr}\text { Major city, Go8 } & 92 & 8 \\ \text { Major city, not Go8 } & 95 & 5 \\ \text { Regional } & 89 & 11\end{array}$

I restrict any holidays with my family and friends to focus on writing my proposals

$\begin{array}{lll}\text { Major city, Go8 } & 90 & 10 \\ \text { Major city, not Go8 } & 86 & 14 \\ \text { Regional } & 89 & 11\end{array}$

Motivation to submit proposals

I submit proposals each year because chance is involved in being funded

$\begin{array}{lll}\text { Major city, Go8 } & 75 & 25 \\ \text { Major city, not Go8 } & 72 & 28 \\ \text { Regional } & 89 & 11\end{array}$

I submit proposals to meet the academic performance requirements of my institution

$\begin{array}{lll}\text { Major city, Go8 } & 60 & 41 \\ \text { Major city, not Go8 } & 57 & 44 \\ \text { Regional } & 78 & 22\end{array}$

I feel pressure from my colleagues to submit proposals

Major city, Go8 $\quad 53 \quad 47$

Major city, not Go8 $\quad 48 \quad 51$

$\begin{array}{lll}\text { Regional } & 78 & 22\end{array}$

Missing data not shown. Row percentage may not add to 100 due to rounding.

${ }^{*}$ Research-intensive university as part of the Go8.

Excerpts were sorted into initial groupings by DLH. These excerpts revealed the themes relating to the impacts on work life and home life. DLH, JC and AGB reviewed these themes and agreed on the coding framework. All comments were then coded by DLH according to the identified themes using NVivo V.9 (QSR International Pty Ltd, 2010). JC reviewed the coding in detail and any minor discrepancies were resolved. Through the analytic process, and the building up of the coding framework, the themes common to each academic level, and Go8 versus non-Go8 universities, were identified. The research team developed the interpretations of these themes with an in-depth discussion to reach a consensus for the analysis. 


\section{RESULTS}

Among 215 researchers, academic level ranged from early career (level A and B) to senior levels (level D and $\mathrm{E}$ ), and almost all were at institutions in major cities $(88 \%)$. More than half of the researchers were currently the recipients of NHMRC Project Grants as CIs, and most of them had submitted proposals in the 2013 funding round. Almost all researchers supported changes to the current NHMRC processes to prepare and submit proposals ( $71 \%$ major changes; $24 \%$ minor changes) and peer review (60\% major changes; $30 \%$ minor changes). More than half of the researchers (59\%) provided extensive comments on the ongoing personal impact of concurrent grant writing and holiday seasons on their work life and home life. The characteristics of those providing comments $(n=127)$ were similar to the complete sample (table 2).

Researchers agreed that preparing their grant proposals always took top priority over other work $(97 \%)$ and personal (87\%) commitments (table 3). Almost all researchers agreed that they became stressed by the workload $(93 \%)$ and restricted their holidays during the grant writing season $(88 \%)$. Most researchers agreed that there were other motivations to submit proposals, including the element of chance in being successful $(75 \%)$, as performance requirements at their institution $(60 \%)$ or because of pressure from their colleagues $(53 \%)$.

A small number of researchers disagreed and reported that preparing their grant proposals did not take over their work (3\%) and they did not become stressed $(7 \%)$. These researchers provided comments on planning ahead and starting early on their proposals. They acknowledged that the system was designed to be tough and reported "those academics who can't handle it shouldn't hold NHMRC grants."

\section{Thematic analysis of work life}

Six major themes are identified for the impact of applying for funding on each of work life and home life (table 4). These themes are described below in descending order of frequency, along with a number of indicative quotes. The quotes have been minimally edited for readability while preserving the meaning; the location of primary institution and academic level of the researcher are in parenthesis.

Table 4 Impact of single annual funding deadline on work life and home life

\begin{tabular}{ll}
\hline Work life themes & Home life themes \\
\hline 1. Top priority & 1. Restricting family holidays \\
2. Career development & 2. Time spent on work at home \\
3. Stress at work & 3. Impact on children \\
4. Benefits at work & 4. Stress at home \\
5. Time spent at work & 5. Impact on family and friends \\
6. Pressure from & 6. Impact on partner \\
colleagues & \\
\hline
\end{tabular}

For work life, the six major themes are: (1) top priority; (2) career development; (3) stress at work; (4) benefits at work; (5) time spent at work and (6) pressure from colleagues.

\section{Work life theme 1: top priority}

Preparing and submitting grant proposals were given top priority over all other work commitments. Gaining funding was important to continue research and maintain staff; however, it came at the cost of stopping current research from progressing.

Without successful grants there is no money for work, no salary and hence no living. (Major city Go8, Level B, ID6)

I feel like my life is on hold for the 1st 2-3 months of the year and that my real work i.e. doing the research and writing papers suffers as a consequence. (Major city Go8, Level D, ID30)

\section{Work life theme 2: career development}

The success or failure of researchers to gain funding has direct impact on their career. Successfully gaining funding was rewarded by future promotion and is the key indicator of being a competitive researcher on the international stage.

If I don't get a grant, I will never be promoted! (Major city Not Go8, Level C, ID59)

Increasing time spent preparing proposals may be seen as an indicator of being uncompetitive or disorganised.

The people who complain about lack of time are those who are unorganised or who have poor ideas/preliminary data for grants. (Major city Not Go8, Level B, ID98)

However, researchers with a competing teaching load need to juggle these competing demands beyond simply being organised or starting early.

Most academics have other commitments, teaching and supervision, occasionally even actually doing research, which takes up a large amount of time at other times of year. (Major city Not Go8, Level C, ID36)

\section{Work life theme 3: stress at work}

Researchers are under considerable stress while preparing their proposals and waiting for peer review reports.

The NHMRC grant system is the single worst aspect of my job as a research academic. (Regional, Level D, ID149)

The stress is largely induced by knowing that the chance of anyone with even a modicum of expertise in your field reviewing your grant is basically zero. (Major city Go8, Level C, ID24) 
Additional pressure is placed on researchers as they acknowledge their low chance of success and question the likelihood of ongoing employment.

It is very stressful to spend a lot of time and effort writing a proposal that has a very low chance of success... Many people anxiously await the grant outcome to see if they are out of work in six weeks. (Major city Not Go8, Level D, ID125)

\section{Work life theme 4: benefits at work}

The benefits of applying for funding were divided into personal benefits (positive) and competitive benefits for peer reviewers (negative). Some researchers acknowledged the personal benefits of writing their proposals as their team brainstormed and refined new scientific ideas.

I do it because our teams do have real sparks that happen during the proposal process which leads to new ideas and new directions. (Major city Not Go8, Level D, ID68)

Other senior researchers reported on the gaming of the peer review process.

It rewards people who know how to 'play the system' rather than the value of the science...there are a lot of people within the system who 'look after each other'. You review for me and I'll review for you. (Major city Not Go8, Level E, ID23)

\section{Work life theme 5: time spent at work}

As the priority at work is to prepare grant proposals, the time spent on other work spreads beyond the standard working day. Researchers work at nights and on weekends, especially those with concurrent teaching roles.

Late nights, neglect staff and students, mental exhaustion, intense frustration with RGMS [the online application system]. (Major city Go8, Level E, ID22)

\section{Work life theme 6: pressure from colleagues}

Some researchers feel pressure from their colleagues to submit proposals to meet the requirements of their institution.

University pressure to submit NHMRC grants because [they are] valued above all else. (Major city Not Go8, Level E, ID14)

The pressure to submit proposals limits the time available to publish which would, in turn, improve the likelihood of being funded.

Grant writing severely impacts on getting papers written... [and] impacts on [my] track record, making it less likely that grants applied for will be funded. (Major city Go8, Level C, ID143)

For senior researchers, their involvement in funding proposals includes the internal review and administration of other proposals, often to the exclusion of contact with their collaborators, junior researchers or students.

\section{Thematic analysis of home life}

For home life, the six major themes are: (1) restricting family holidays; (2) time spent on work at home; (3) Impact on children; (4) stress at home; (5) impact on family and friends and (6) impact on partner.

\section{Home life theme 1: restricting family holidays}

The conflict between the single annual funding deadline and spending holidays with children and family is a recurring issue for researchers with family responsibilities. Most university research offices require the application up to 5 weeks before the deadline so that most researchers work on the application over the Australian summer when the community takes extended Christmas holidays. The summer holiday season is also the longest school holiday period (6-8 weeks) in Australia, and many researchers express their frustration and guilt at not spending more time with their children and families.

The process is too involved with a very low success rate, and is poorly timed over Christmas holidays! This year I opted out of applying to improve my family. (Major city Go8, Level C, ID27)

My family chose to go away without me, or not to go away at Christmas time. (Major city Go8, Level D, ID28)

Other researchers report the absence of university support during grant writing season when administrative staff are on their summer holidays.

Just when most academics are due for a break, right when most universities shut down and take offline all of their support services, RGMS [online application process] opens up. (Major city Not Go8, Level D, ID20)

\section{Home life theme 2: time spent on work at home}

For most researchers, the only solution to managing their workload is to work at home in the evenings and on weekends, even while on holidays or recovering from health issues.

My life is completely dominated by the need to get the grant applications completed on time-I almost can't think of anything else for 2-3 months! (Major city Not Go8, Level C, ID40)

I have sacrificed personal time, holidays, many social and work commitments, sleep, exercise and much more to devote months to writing grants. (Major city Not Go8, Level E, ID91)

Some researchers questioned why they continue in a research career with such uncertainty and significant negative impacts on their health. 
It makes me ill. I have developed migraine phenotypes for the first time in my life whilst writing grants. (Major city Go8, Level D, ID87)

This year was particularly bad and by the end of it I was an emotional wreck. (Major city Go8, Level C, ID159)

\section{Home life theme 3: impact on children}

Researchers with responsibilities for children, especially young children, express their frustration and guilt as they 'neglected' their children to give top priority to their grant writing.

I have a young family and our lives are put on hold for 3 months at the worst possible time of year. We have to pay for childcare so there is a huge financial cost plus the personal cost of not being with my children. (Major city Go8, Level B, ID19)

My husband and I are both researchers funded by the NHMRC and we have two young children. We are finding this time incredibly stressful and often feel as if our children are being disadvantaged through lack of quality parenting time. (Major city Go8, Level C, ID51)

Many researchers are appalled at the lack of family friendly policies around the timing for Australian funding schemes.

What should be the happiest time of the year (kids on holiday, summer, Christmas) is now the most stressful because of the perfect storm of ARC \& NHMRC grant deadlines and teaching commitments for the new year. (Major city Not Go8, Level C, ID101)

An early career researcher reported on the guilt felt from being absent for important events in their child's life while preparing their proposal:

You will always have mother's guilt, now I have grant writing guilt! (Major city Go8, Level A, ID55)

\section{Home life theme 4: stress at home}

The stress on researchers during preparation of their proposals overflows into their personal lives and family relationships. Researchers are stressed and lead unhealthy lifestyles during grant writing season, and the rest of the household is negatively impacted.

Negative impact on sleep and health, family life, school holiday period; on domestic chores, cleanliness, tidiness and healthy eating at home...makes me angry! (Major city Go8, ID34)

This also had flow on effects for family life...[a] tired and cranky, stressed family member (me) was very disruptive to family life. (Major city Not Go8, Level A, ID69)

The low chance of success further adds to the stress as researchers consider the impact of unsuccessful proposals on their continuing employment and providing for their family.

I feel depressed by the fact that grants that received very good [ peer review] comments got culled, [and] not even being ranked. (Major city Go8, Level B, ID117)

\section{Home life theme 5: impact on family and friends}

The grant writing season directly impacts on researchers' personal relationships and carer responsibilities for children and ageing parents. The 'annual problem' of grant season is an ongoing issue for personal relationships that must either adapt to the seasonal restrictions or be sidelined.

My family hates my profession. Not just my partner and children, but my parents and siblings. The insecurity despite the crushing hours is a soul destroying combination that is not sustainable. (Major city Go8, Level B, ID19)

Only the strongest relationships survive...I focus on only the closest family members [for] maintaining relationships. Other relationships have had to adapt to the annual problem or, more often, disintegrate. (Major city Go8, Level D, ID26)

\section{Home life theme 6: impact on partner}

In addition to comments on family and friends that include their partner, some researchers specifically report the impact on their partner. Having a supportive partner is crucial for some researchers to have sufficient time to prepare their proposals.

I limit family holidays, spend less time with my young children (particularly during their summer school holidays) and I get almost no other research work done for 3 months. This is only possible because my partner is very understanding. (Major city Go8, Level E, ID108)

My spouse had to take over a lot of my responsibilities at home... due to the instability of a research job, he is the main breadwinner at home, and [he also] has a very stressful, demanding job. (Major city Not Go8, Level B, ID36)

\section{Mental health and well-being}

Additional impacts on mental health and well-being were identified through comments including 'incredible anxiety', 'depressed', 'despondent', 'insecurity' and 'souldestroying'. The mental health and welfare of researchers warrants further examination beyond this study.

\section{DISCUSSION}

\section{Workload, stress and family}

The current study provides the first empirical evidence of the personal experience of Australian researchers as applicants for funding. It provides strong indications of worker stress and burnout. Anecdotal stories of the impact of grant writing are common in conversations among researchers, especially those with young children. ${ }^{19}$ The 
findings from our study provide the empirical evidence that grant writing has significant negative impact on researchers' personal lives, health and well-being.

Our findings showed that some researchers were willing to accept the workload to prepare grant proposals. Others felt there was little choice but to accept the tough reality of seeking research funding in Australia. Academic career development and continuing employment depend strongly on successfully obtaining funding, and this was accepted as the status quo for research careers. Another reason motivating researchers to submit grant proposals was that institutions expect their researchers to apply for funding regardless of their likely chance of success. There is a general atmosphere of pressure from colleagues to submit proposals. As a consequence, the time demands required to prepare proposals can move the pressure of other workloads onto colleagues.

\section{Strengths and limitations}

This is the first Australian study providing empirical evidence of the significant negative impact of applying for funding on researchers' productivity, health and wellbeing. It also provides first-time evidence of impact on home and family life due to the grant writing season for the major Australian funding source for health and medical research. Furthermore, it highlights the problems in Australia arising from preparing proposals for a single annual funding deadline.

Researchers responding to the survey may not be representative of the complete population of researchers. However, our sample did report a history of successfully gaining funding from NHMRC Project Grants. Researchers from early career (level A) to professor (level E) provided comments on their personal lives, so the difficulties were not just confined to new academics who may not know how to negotiate the funding system or are disorganised. A larger sample of researchers from major cities is unlikely to alter the findings from the qualitative analysis. Researchers from regional areas were a minority and a larger sample may provide for comparisons between researchers in regional areas and major cities. The costs to the mental health and well-being of the researcher or their family members could not be quantified in this study and requires further examination.

\section{Funding deadlines}

A single annual deadline places enormous pressure on Australian researchers to prepare their proposals. Changing the timing of the annual funding scheme, or following international schemes with multiple rounds per year, will have wide-ranging benefits for Australian researchers, especially those with children. ${ }^{19}$ Successfully gaining annual funding is one of the most important tasks researchers need to achieve. Sometimes, researchers feel pressure to apply for inappropriate reasons or before they have a competitive track record. Researchers go to extraordinary lengths to prepare good proposals, often sacrificing family time and personal relationships. Much of the stress comes from having a heavily bureaucratic process that demands a lot of work and data from researchers for a single annual deadline. The grant writing season may only last over 3 summer months; however, researchers place enormous importance on this time because the consequences are a delay of 1 year before the next opportunity to apply.

\section{Work-home conflict}

The impact of funding schemes on workplace stress in an academic environment has been examined. A survey of over 1100 US research administrators from 2007 to 2010 found that almost $90 \%$ of administrators had increasing work demands and stress, with increasing impact on their family responsibilities. ${ }^{20}$ Although Shambrook ${ }^{20}$ focused specifically on research administrators and not the academic researchers, the findings highlight the personal costs of applying for funding that spreads beyond the lead investigators. More than a decade of research has been conducted on the impact of having children on the careers of tenure-track US academics. ${ }^{21}$ Equivalent tenure-track positions do not exist for Australian academic researchers; therefore, the need to secure research funding is imperative for continuing employment to provide for their families.

The personal cost and stress of being an Australian academic has been investigated. The National University Stress Study compared two surveys (2000 and 2003/4) of 447 academics and found that increasing work pressure predicted increasing work-home conflict and psychological strain. ${ }^{22}$ Another survey from 2004 to 2008 showed that Australian academics were less satisfied with their work-home balance compared with employees in other industries. ${ }^{23} 24$ Advances in technology have added to the personal workloads of all Australians, creating time poverty and household stress. ${ }^{25}$ The mobility provided by a laptop and home internet connection facilitates the work-home conflict as researchers can continue their research and grant writing at almost any time. Furthermore, researchers under pressure to manage their workload may find it difficult to resist confining work to normalised hours.

The negative impacts of grant writing on personal and family life are usually anecdotal or hidden in the grey literature $^{1926}$ and go unreported in publications on academic work life. Other research focuses on the burden on peer reviewers and administrators and not the applicants. $^{27}$ Innovative policies from funding agencies can reduce the burden on applicants and facilitate the reduction in personal workloads on researchers and be more family friendly. The personal impact of unsuccessful proposals with a lack of feedback on the reasons for failure may be adding to the negative experiences of researchers as applicants. Anecdotally, some researchers have been depressed and despondent about trying again in the next funding round. The level of mental health 
and mood disorders of researchers during the funding rounds needs to be explored.

\section{CONCLUSION}

As demonstrated by international funding agencies, having more than a single annual deadline would distribute the funding opportunities across the year. The process of preparing grant proposals for a single annual deadline is stressful, time consuming and conflicts with family responsibilities. The timing of the funding cycle could be shifted to minimise applicant burden, give Australian researchers more time to work on actual research and to be with their families.

\section{Author affiliations}

${ }^{1}$ School of Public Health and Social Work \& Institute of Health and Biomedical Innovation, Queensland University of Technology, Brisbane, Queensland, Australia

${ }^{2}$ School of Medicine, Flinders University, Adelaide, South Australia, Australia

${ }^{3}$ Melbourne School of Population and Global Health, The University of Melbourne, Melbourne, Victoria, Australia

Acknowledgements The authors are grateful to the Australian researchers who provided the survey data.

Contributors DLH, PC, NG and AGB conceived and designed the study. DLH and $A G B$ analysed the descriptive data. DLH and JC analysed the qualitative data. All authors interpreted the data, drafted the article or revised it critically for important intellectual content and approved the version to be published. AGB is the study chief investigator and guarantor.

Funding This work was funded by the National Health and Medical Research Council (NHMRC Project Grant number 1023735).

Competing interests DLH salary is supported from NHMRC funding. JC receives funding from NHMRC, Australian Research Council (ARC) and several other state funding agencies. PC receives funding from NHMRC, NIH and several other national and international health funding agencies. NG receives funding from NHMRC, ARC, National Institute for Health Research (NIHR), Queensland (QLD) Government and is the academic director of the Australian Centre for Health Services Innovation. AGB receives funding from NHMRC and QLD Government.

Ethics approval Queensland University of Technology Ethics Committee (1300000210)

Provenance and peer review Not commissioned; externally peer reviewed.

Data sharing statement All the data collected as part of this study are available to interested researchers through ethical approval from the QUT Human Research Ethics Committee. Please contact AGB (a.barnett@qut.edu. au) if you are interested in accessing the data

Open Access This is an Open Access article distributed in accordance with the Creative Commons Attribution Non Commercial (CC BY-NC 3.0) license, which permits others to distribute, remix, adapt, build upon this work noncommercially, and license their derivative works on different terms, provided the original work is properly cited and the use is non-commercial. See: http:// creativecommons.org/licenses/by-nc/3.0/

\section{REFERENCES}

1. Bonetta L. Enhancing NIH grant peer review: a broader perspective. Cell 2008;135:201-4.

2. Van Noorden R, Brumfiel G. Fixing a grant system in crisis. Nature 2010;464:474-5.
3. Canadian Institutes of Health Research. Designing for the future: the new open suite of programs and peer review process. Ontario: CIHR, 2013. http://www.cihr-irsc.gc.ca/e/documents/or_des_for_ future-en.pdf

4. Guthrie $\mathrm{S}$, Guerin $\mathrm{B}, \mathrm{Wu} \mathrm{H}$, et al. Alternatives to peer review in research project funding. RAND Europe. 2013. http://www.rand.org/ pubs/research_reports/RR139.html

5. Australian Government. Strategic review of health and medical research in Australia: better health through research. Canberra: Department of Health and Ageing, 2013. http://www.mckeonreview. org.au

6. Herbert DL, Barnett AG, Clarke $P$, et al. On the time spent preparing grant proposals: an observational study of Australian researchers. BMJ Open 2013;3:e002800.

7. Herbert DL, Barnett AG, Graves N. Funding: Australia's grant system wastes time. Nature 2013;495:314.

8. Alberts B. Overbuilding research capacity. Science 2010;329:1257.

9. National Health and Medical Research Council. Research funding facts book 2012. Canberra: NHMRC, 2013. http://www.nhmrc.gov. au/_files_nhmrc/publications/attachments/nh161_nhmrc_funding facts_book_130809.pdf

10. National Health and Medical Research Council. Funding rate and funding by funding scheme. Canberra: NHMRC, 2013. http://www. nhmrc.gov.au/grants/outcomes-funding-rounds

11. Barnett AG, Herbert DL, Clarke P, et al. The research lottery: the pressures on the Australian grant system. Aust Q 2014;85:4-9.

12. European Science Foundation. European peer review guide: integrating policies and practices into coherent procedures. 2011 http://www.esf.org

13. Engineering and Physical Sciences Research Council. Funding guide. Arrangements and procedures for research grants and research fellowships. Swindon: EPSRC, 2013. http://www.epsrc.ac uk/SiteCollectionDocuments/FundingGuide.pdf

14. Medical Research Council. Handbook for applicants and grant holders. London: MRC, http://www.mrc.ac.uk/Fundingopportunities

15. National Institutes of Health. SF424 (R\&R) application guide for NIH and other PHS agencies. USA: NIH, 2013. grants.nih.gov/Grants/ funding/424/SF424_RR_Guide_General_Adobe_VerB.pdf

16. National Science Foundation. Grant proposal guide. USA: NSF 2011:I-3. http://www.nsf.gov/pubs/policydocs/pappguide/nsf11001/ gpgprint.pdf

17. Wood F, Wessely S. Peer review of grant applications: a systematic review. In: Godlee F, Jefferson T, eds. Peer review in health sciences. 2nd edn. London: British Medical Association Publications, 2003:14-44.

18. Australian Bureau of Statistics. Australia remoteness area, Australian Standard Geographical Classification (ASGC). Canberra: ABS, 2006. http://www.abs.gov.au/AUSSTATS

19. Jacobson K. Six steps to fairer funding for female scientists. Conversation 2013. http://theconversation.com/ six-steps-to-fairer-funding-for-female-scientists-16895

20. Shambrook JF. Comparison of stress-related factors in the 2007 and 2010 Research Administrator Stress Perception Surveys (RASPerS). $J$ Res Adm 2012;43:107-18.

21. Mason MA, Wolfinger NH, Goulden M. Alone in the ivory tower. Do babies matter? Gender and family in the ivory tower. New Jersey: Rutgers University Press, 2013. Ch. 4:59-82. http://rutgerspress. rutgers.edu/product/Do-Babies-Matter,4767.aspx

22. Winefield T, Boyd C, Saebel J, et al. Update on National University Stress Study. Aust Univ Rev 2008:50:20-9.

23. Langford $\mathrm{PH}$. Benchmarking work practices and outcomes in Australian universities using an employee survey. J Higher Educ Policy Manage 2010;32:41-53.

24. Bentley PJ, Coates H, Dobson IR, et al. Factors associated with job satisfaction amongst Australian university academics and future workforce implications. In: Job satisfaction around the academic world. Dordrecht: Springer, 2012:29-54.

25. Pocock B, Skinner N, Williams P. Time bomb: work, rest and play in Australia today. Sydney: New South Publishing, 2012.

26. Decker RS, Wimsatt L, Trice AG, et al. A profile of federal-grant administrative burden among Federal Demonstration Partnership faculty. USA: Faculty Standing Committee of the Federal Demonstration Partnership, 2007. http://www.iscintelligence.com/ archivos subidos/usfacultyburden 5.pdf

27. Demicheli V, Di Pietrantonj C. Peer review for improving the quality of grant applications. Cochrane Database of Syst Rev 2007;(2): MR000003. 